\title{
Editorial
}

\section{Mais trabalhos, mais qualidade}

Para a primeira ediçấo de 2012 (e o $12^{\circ}$ ano de existência da revista), propomos a nossos leitores e assinantes um conjunto de artigos originais e revisões, representativo da atualidade da pesquisa brasileira em fisioterapia.

Do lado dos tratamentos, publicamos vários resultados de trabalhos sobre o método de reabilitação aquática Watsu na fibromialgia (Guilherme Carlos Brech e equipe), do isostretching no movimento da coluna lombar (Ana Carolina Brandt de Macedo e equipe), e do Pilates na melhoria da marcha e do equilíbrio dos idosos (Milson Carvalho Quadros Júnior e equipe). Já publicamos nas ediçôes anteriores vários artigos sobre o método Pilates, sempre carente de estudos científicos.

Outra especialidade da fisioterapia bastante frequente em nossas páginas é a da saúde da mulher, hoje com um estudo de Fabiana Flores Sperandio e equipe (Udesc, Florianópolis) sobre a importância da incontinência urinária na climatério e sua relação com os fatores sócio-econômicos. Este trabalho mostra a importância e a complexidade dos fatores a ser considerados para melhorar a qualidade de vida das mulheres, den- tre os quais os autores sugerem a presença de fisioterapeutas especializados na prevenção e no tratamento das disfunçóes uro-ginecologicas no atendimento hospitalar.

$\mathrm{Na}$ mesma ordem de idéias, um trabalho realizado por Rafaela Silva Rodrigues e uma equipe da Bahia mostra a importância da inserção de fisioterapeutas nas Unidades Básicas da Estratégia Saúde da Família.

Enfim, destacamos a revisão de LC Cameron, Adriana Bassini e sua equipe da UniRio, sobre a fisiopatologia da doença pulmonar obstrutiva crônica, e, consequentemente, a compreensão da utilização dos recursos da atividade física e dos complementos nutricionais nesta doença crônica.

Estes trabalhos são apenas alguns dos que podem encontrar nesta edição. Cada ano tentamos aumentar o número de artigos publicados e agilizar o procedimento editorial para reduzir o tempo de espera entre o recebimento e a publicação. Em média, o tempo de espera diminuiu para 4 a 6 meses, e esperamos, em um futuro próximo, melhorar este resultado pela utilização de procedimentos de avaliação online.

\section{Erratum}

$\mathrm{Na}$ edição de novembro/dezembro de 2010, substituímos a Figura 1 do artigo "Método Pilates: uma introdução ao seu entendimento cinesiológico" na página 451 por outra. Aqui a verdadeira figura. Desculpem-nos pelo erro.

Figura 1 - Ilustração da tarefa. A fase 1 é caracterizada pelo movimento da posição inicial (flexâo) até o alvo (extensäo); a fase 2 é caracterizada pela manutenção da postura no alvo (extensão) e a terceira fase é caracterizada pelo movimento de retorno à posição inicial (flexão).

Fase 1

Fase 2

Fase 3

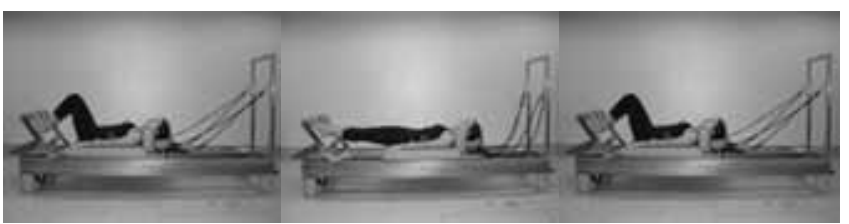

